\title{
Major histocompatibility complex (MHC) variation and susceptibility to the sea louse Lepeophtheirus salmonis in Atlantic salmon Salmo salar
}

\author{
K. A. Glover ${ }^{1, *}$, U. Grimholt ${ }^{2}$, H. G. Bakke ${ }^{2}$, F. Nilsen ${ }^{1}$, A. Storset $^{3}$, Ø. Skaala ${ }^{1}$ \\ ${ }^{1}$ Institute of Marine Research, PO Box 1870, Nordnes, 5817 Bergen, Norway \\ ${ }^{2}$ Norwegian School of Veterinary Science, PO Box 8146 Dep, 0033 Oslo, Norway \\ ${ }^{3}$ Aqua Gen AS, PO Box 1240, Pirsenteret, 7462 Trondheim, Norway
}

\begin{abstract}
The relationship between genetic variation in major histocompatibility complex (MHC) Class I and II genes and susceptibility to sea lice Lepeophtheirus salmonis (Krøyer) in Atlantic salmon Salmo salar (L.) was studied in cage-reared post smolts. Polymorphic repeat markers located in the 3' untranslated regions (3UTR) of the genes Sasa-UBA (MHC Class I) and Sasa-DAA (MHC Class II) were screened in 1004 fish sampled from 11 full-sibling families. This gave rise to a total of 7 and 5 alleles, and 17 and 13 genotypes respectively. Significant relationships between both Sasa-UBA-3UTR and Sasa-DAA-3UTR genotypes and abundance of lice were observed within the pooled material, within individual families, and within the pooled material with both markers combined. However, most of these associations were either weak, linked with variation in fish size among genotypes, or influenced by family background genome. Nevertheless, within one family, the Sasa-DAA-3UTR 248/278 genotype displayed a significantly higher (33\%) abundance of lice compared with the SasaDAA-3UTR 208/258 genotype, and this difference was not influenced by fish size. Consequently, the results of this study indicate a link between MHC Class II and susceptibility to lice.
\end{abstract}

KEY WORDS: Lepeophtheirus salmonis $\cdot$ Salmon $\cdot$ MHC $\cdot$ Susceptibility $\cdot$ Resistance

Resale or republication not permitted without written consent of the publisher

\section{INTRODUCTION}

The sea lice Lepeophtheirus salmonis (Krøyer) and Caligus elongatus (Nordmann) continue to represent a major challenge for the salmon farming industry. Atlantic salmon Salmo salar (L.) smolts placed into seacages often become infected with lice, and the farmer needs to control this infection level. Although a range of techniques are employed to control sea lice infections, including the use of cleaner wrasse (Deady et al. 1995, Tully et al. 1996, Treasurer 2002), the primary method involves the use of oral or bath-administered chemotherapeutics (Wootten et al. 1982, Roth et al. 1993, Mordue \& Pike 2002).

Examples of sea lice displaying reduced sensitivity to chemotherapeutic agents have been documented (Jones et al. 1992, Treasurer et al. 2000, Tully \& McFadden 2000, Sevatdal \& Horsberg 2003, Fallang et al. 2004), and it is likely that this will become more extensive with continued widespread use of these agents. It is apparent that alternative sea lice control strategies are required for the future of salmon aquaculture. Vaccines (Roper et al. 1995, Raynard et al. 2002, Frost et al. 2006) in addition to selective breeding aimed to reduce the sensitivity of farmed salmon to sea lice infection (Mustafa \& MacKinnon 1999, Glover et al. 2004a, 2005, Kolstad et al. 2005, Glover \& Skaala 2006) are being considered as alternative control measures.

In an opportunistic study of genetic variation in the susceptibility of Atlantic salmon to Caligus elongatus, Mustafa \& MacKinnon (1999) estimated heritability in susceptibility to this trait to be 0.22 . In the first published estimate of susceptibility to Lepeophtheirus salmonis, Glover et al. (2005) estimated broad-sense heritability to be $0.07( \pm 0.02)$ among 30 full-sibling Atlantic salmon families reared in a single cage. The third estimate of susceptibility to sea lice in Atlantic 
salmon was published by Kolstad et al. (2005). These authors produced multiple estimates of heritability for total abundance of $L$. salmonis in several year classes of Atlantic salmon, giving heritability values from 0.06 $( \pm 0.04)$ to $0.19( \pm 0.03)$, with a mean from 3 year classes of $0.14( \pm 0.02)$. Taken together, data from these studies indicate that there is sufficient genetic variation to decrease the susceptibility of farmed Atlantic salmon to sea lice through selective breeding. However, the estimated degree of heritability for this trait may be regarded as relatively low compared with many other traits currently selected for in salmon breeding (Gjedrem 2000).

If a selective breeding program for reducing the susceptibility of farmed Atlantic salmon to lice is to be successful, there is a need to be able to accurately select families and individuals that display decreased sensitivity to lice. In addition to genetic background at the population (Glover et al. 2001, 2003, 2004b, Glover \& Skaala 2006) and family level (Mustafa \& MacKinnon 1999, Glover et al. 2005, Kolstad et al. 2005), a range of known and unknown factors influence sea lice infections in fish, including fish size (Jaworski \& Holm 1992, Todd et al. 2000, Glover et al. 2001, 2003, 2004a,b, Tucker et al. 2002, Genna et al. 2005, Glover \& Skaala 2006), stress (Johnson \& Albright 1992a) and a combination of light, salinity and host velocity (Genna et al. 2005). Consequently, it has been suggested that simply selecting individual salmon and families that display lower than average sea lice infections compared with the population in which selection is to be practised may not give an optimal response to selection (Glover et al. 2005, Glover \& Skaala 2006). Furthermore, accurately and consistently counting lice infections on thousands of salmon in a commercial breeding program in which other traits are also selected for may present considerable practical challenges.

Infections with a parasite (from virus and bacteria to complex eukaryotic parasites) will typically induce a host response. This response varies depending on the host-parasite interaction (i.e. whether it is an intracellular, internal or external parasite) and commonly involves both the innate and acquired immune system. For ectoparasites, the immune response must be effectuated through the skin and other parts of the host (e.g. blood) that the parasites encounter. The major histocompatibility complex (MHC) system is an important part of the vertebrate immune system, and it has been shown that MHC allele diversity is important for resistance against parasites (e.g. Wegner et al. 2006).

In salmonids, significant associations between MHC genotype and susceptibility to bacterial (Langefors et al. 2001, Grimholt et al. 2003) and viral (Ozaki et al. 2001, Palti et al. 2001, Grimholt et al. 2003, Miller et al. 2004, Kjoglum et al. 2006) pathogens have been docu- mented. Data from other fish species have indicated that MHC variation may be linked with susceptibility to parasites (e.g. Kurtz et al. 2004, Simkova et al. 2006, Wegner et al. 2006). Thus far, the potential link between genetic variation in the MHC in Atlantic salmon and susceptibility to sea lice has not been investigated. Consequently, the aim of the present study was to investigate the relationship between genetic variation in the MHC in Atlantic salmon and susceptibility to sea lice infection.

\section{MATERIALS AND METHODS}

Fish and rearing. The salmon used in this study were 7th generation domesticated fish originating from a Norwegian salmon breeding program. The breeding population was first established in the early 1970s and is at present controlled by Aqua Gen AS. This has been and continues to be one of the major farmed strains in Norway. Further details of the genetic origin of fish comprising this stock can be obtained from Gjedrem et al. (1991). Fifteen full-sibling families were established from the breeding stock in the autumn of 2002. Fertilised eggs were incubated, hatched and reared in single-family tanks. In June 2003, approximately 200 ind. from each family were tagged with passive integrated transponders (PIT) and transferred to a single freshwater tank $\left(2 \mathrm{~m}^{3}\right)$ for continued rearing. On 4 May 2004, these fish were transferred to a single $1200 \mathrm{~m}^{3}$ marine net-pen at a breeding station located at Hemne, central Norway. In the cage the fish were fed a commercial diet (Biomar) by hand according to standard feeding tables utilised by Aqua Gen AS.

Monitoring of lice infection and sampling. Starting 2 wk post transfer to salt-water, a sample of 10 salmon were sampled by a hand-net from the cage on a weekly basis to inspect fish for lice infection. These individuals were removed from the experiment.

The experiment was terminated between 27 September and 2 October, when there was close to $100 \%$ prevalence of lice on sampled fish and mean abundance of adult and pre-adult lice was $>5$. Termination involved removing small groups of fish (5 to 10) from the cage by wet net and placing them into a large white bucket containing $30 \mathrm{l}$ water and an overdose of the anaesthetic benzocaine. Sedated fish were killed by a sharp blow to the head and placed into individual white buckets. This operation was performed in a quick and efficient manner such that potential for loss of lice in the anaesthetic bath was minimised. Using a similar sampling strategy, Glover et al. (2003) observed sampling-induced lice losses of 2.8 and $3.4 \%$. Fish placed in white buckets were immediately taken into the laboratory and examined. Fish length, weight and 
PIT-tag identification number were noted, and numbers of lice recorded. The white bucket in which the fish was transported was inspected for loss of lice, and these were removed and added to the individual's lice count. Initial inspection of the fish revealed that the mobile adult and pre-adult stages represented over $95 \%$ of the population of lice on these fish at the time of sampling. Consequently, only numbers of Lepeophtheirus salmonis and Caligus elongatus were recorded; louse sex and developmental stage were not recorded. In total, lice were counted on 1342 salmon excluding a small number of individuals that were not included in the data set (15 fish), which had either fallen onto the floor when sampling or contained unreadable PIT tags.

MHC genotyping. A total of 1004 individual fish selected randomly from 11 of the 15 families were selected for genotyping. Genomic DNA from these individuals was isolated in 96 well-plate format using the standard protocol for the Qiagen DNA isolation kit.

The polymorphic repeats located in the $3^{\prime}$ untranslated regions (3UTRs) of Sasa-UBA (MHC Class I) and Sasa-DAA (MHC Class II) genes (Grimholt et al. 2002, Stet et al. 2002) were amplified using the fluorescently labelled sense primers 5'-GGAGAGCTGCCCAGATG ACTT-3' and 5'-GATGGCAAAGAGGAAAGTGAG-3' and the reverse primers $5^{\prime}$-CAATTACCACAAGCCC GCTC-3' and 5'-TTGTTATGCTCTACCTCTGAA-3'. The PCR conditions were 50 ng genomic DNA per $10 \mu \mathrm{l}$ total reaction volume for 25 cycles at $56^{\circ} \mathrm{C}$ annealing temperature. Markers were analysed using automated ABI 377 machines (Applied Biosystems).

Statistics. All statistical analysis was performed in the program STATISTICA version 7.0 (StatSoft). Families were compared for infection levels and mean weight using ANOVA and ANCOVA where continuous variables were included in the statistical design. Significance tests were followed by Tukey's post hoc test for unequal N. Correlation was used to describe potential relationships between fish size and infection level within each family, within the pooled material including all families, and using mean family values.

Abundance of lice for the Sasa-UBA3UTR and Sasa-DAA-3UTR genotypes was analysed for each marker separately within families and within pooled families. These data were analysed by ANCOVA, where individual fish weight was implemented as the continuous predictor. Significant tests were investigated further by Tukey's post hoc test for unequal N. In order to investigate the potential effect of variation within the 2 markers simultaneously on louse infection, composite genotypes (Sasa-UBA-3UTR-Sasa-DAA-3UTR) were established for all individuals. Composite genotypes represented by 20 or more fish within the pooled material were compared with each other (in terms of abundance of lice) by ANCOVA. This analysis was restricted to pooled family data. In families displaying significant relationships between genotype and abundance of lice, G-tests were used to test for random sampling of alleles.

\section{RESULTS}

\section{General infection data}

A total of 1342 fish originating from 15 full-sibling families were sampled for lice. At the time of sampling, Caligus elongatus displayed a very low abundance on the experimental fish and only 45 parasites were recorded in the entire material. Consequently, data from $C$. elongatus were excluded from statistical analysis. The summary statistics of the infection data for Lepeophtheirus salmonis are presented in Table 1. Significant differences in mean weight (ANOVA, $\left.F_{14,1327}=33.5, \mathrm{p}<0.0001\right)$ and abundance of L. salmonis (ANOVA, $F_{14,1327}=9.3, \mathrm{p}<0.0001$ ) were observed among the families. Mean weight varied by a factor of 2.47 among the families, whilst mean L. salmonis abundance varied by a factor of 1.36 . Out of 105 pairwise post hoc comparisons for mean family abundance of L. salmonis, 25 were significant, indicating that a number of families were responsible for the observed trend. Within families, abundance of L. salmonis among individual salmon varied greatly. The range in abundance of $L$. salmonis varied from between 11 and

Table 1. Salmo salar. Summary statistics for 15 Atlantic salmon families infected with sea lice Lepeophtheirus salmonis

\begin{tabular}{|c|c|c|c|c|c|}
\hline Family & $\mathrm{N}$ & $\begin{array}{l}\text { Weight g } \\
\text { (SE) }\end{array}$ & $\begin{array}{c}\text { Mean louse } \\
\text { abundance (SE) }\end{array}$ & $\begin{array}{l}\text { Median louse } \\
\text { abundance }\end{array}$ & Range \\
\hline 1 & 87 & $461.8(18.4)$ & $19.9(0.65)$ & 20.0 & $7-42$ \\
\hline 2 & 106 & $766.9(16.7)$ & $23.5(0.59)$ & 24.0 & $7-45$ \\
\hline 3 & 82 & $518.6(19.0)$ & $19.6(0.67)$ & 19.0 & $4-31$ \\
\hline 4 & 113 & $446.9(16.2)$ & $19.2(0.57)$ & 19.0 & $7-38$ \\
\hline 5 & 76 & $371.7(19.7)$ & $19.9(0.70)$ & 18.0 & $6-56$ \\
\hline 6 & 122 & $451.3(15.6)$ & $18.5(0.55)$ & 18.5 & $7-44$ \\
\hline 7 & 64 & $309.9(21.5)$ & $19.1(0.75)$ & 18.0 & $9-32$ \\
\hline 8 & 92 & $441.4(18.0)$ & $17.5(0.63)$ & 17.0 & $6-53$ \\
\hline 9 & 94 & $557.7(17.7)$ & $23.3(0.62)$ & 23.0 & $9-47$ \\
\hline 10 & 51 & $423.9(24.1)$ & $21.4(0.84)$ & 21.0 & $9-35$ \\
\hline 11 & 97 & $502.1(17.5)$ & $22.1(0.61)$ & 22.0 & $9-41$ \\
\hline 12 & 108 & 411.9 (16.5) & $20.4(0.58)$ & 21.0 & $9-39$ \\
\hline 13 & 88 & 461.6 (18.3) & $20.6(0.64)$ & 20.0 & $11-35$ \\
\hline 14 & 104 & 401.6 (16.9) & $17.3(0.59)$ & 17.0 & $4-52$ \\
\hline 15 & 58 & $467.6(22.6)$ & $21.3(0.79)$ & 21.0 & $9-33$ \\
\hline
\end{tabular}


35 within the family displaying the least variation to between 4 and 52 in the family displaying the greatest variation.

Fish size is an important factor influencing infection level with sea lice (Jaworski \& Holm 1992, Todd et al. 2000, Glover et al. 2001, 2003, 2004a,b, Tucker et al. 2002, Glover \& Skaala 2006). Within the pooled material, including data from all 15 families, a weak but nevertheless significant positive relationship between individual fish weight and abundance of Lepeophtheirus salmonis was observed $\left(\mathrm{R}^{2}=0.07\right.$, $\mathrm{N}=1342, \mathrm{p}<0.0001$ ). In addition, a significant positive relationship between mean family weight and mean family abundance of $L$. salmonis was observed $\left(\mathrm{R}^{2}=0.43, \mathrm{~N}=15, \mathrm{p}<0.0001\right)$ (Fig. 1). The relationship between individual fish size and abundance of L. salmonis was investigated within each of the 15 families separately. Correlations ranged from $\mathrm{R}^{2}=$ 0.0002 ( $\mathrm{p}=0.89)$ to $\mathrm{R}^{2}=0.19(\mathrm{p}<0.0001)$, with 7 of the 15 tests giving significant p-values with $95 \%$ confidence. When the significance level was adjusted for multiple independent tests (15 tests, new significance level $\mathrm{p}=0.003$ ), 4 of the 15 tests were still significant, indicating that some families displayed significant relationships between fish weight and abundance of L. salmonis. All significant relationships were positive, i.e. larger fish displayed a higher abundance of L. salmonis.

Despite variable relationships between individual fish size and abundance of Lepeophtheirus salmonis at the individual, family, and pooled levels, the observed variation in mean $L$. salmonis abundance among families was still significant when the analyses were performed with fish weight as a continuous predictor (ANCOVA, family effect: $F_{14,1326}=5.9, \mathrm{p}<0.0001$ );

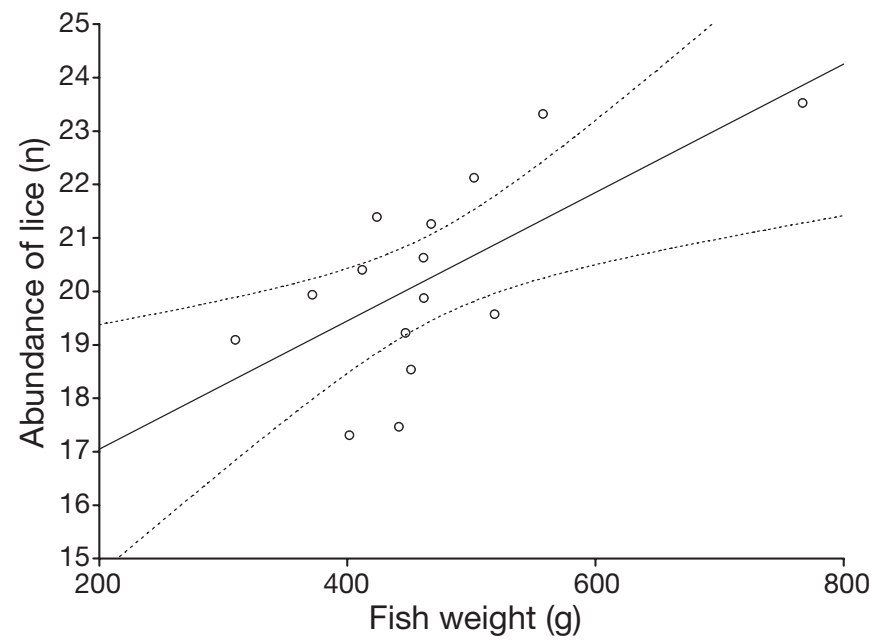

Fig. 1. Salmo salar and Lepeophtheirus salmonis. Relationship between mean fish weight and abundance of sea lice for 15 full-sibling families. $\mathrm{R}^{2}=0.43, \mathrm{~N}=15, \mathrm{p}<0.0001$ however, weight had a more significant influence on the infection level (ANCOVA, individual weight: $\left.F_{1,1326}=45.4, \mathrm{p}<0.0001\right)$.

\section{Genotyping results}

A random selection of individuals $(\mathrm{N}=1004)$ from 11 of the 15 families were chosen for genotyping. Not all individuals produced readable genotypes for both Sasa-UBA-3UTR and Sasa-DAA-3UTR. Consequently, the numbers of individuals analysed for either of these 2 markers are lower than the total number of individuals selected for genotyping. These individuals include samples that failed to produce readable genotypes after one set of re-runs and were thus excluded from the analyses. Numbers of individual fish analysed per family for each marker ranged from 72 to 107 .

For Sasa-UBA-3UTR, a total of 7 alleles ranging from 314 to 336 bp were detected within the 11 families, giving 17 genotypes across families. For Sasa-DAA-3UTR, 5 alleles were detected in the range from 208 to $278 \mathrm{bp}$, giving a total of 13 genotypes across families. Fish were sorted into genotypes both within families and among families in order to investigate potential effects of MHC genotype on abundance of Lepeophtheirus salmonis.

\section{Genotype vs. abundance of Lepeophtheirus salmonis: families pooled}

The relationship between genotype vs. fish weight and genotype vs. abundance of Lepeophtheirus salmonis for both markers are presented in Fig. 2. Significant differences in abundance of lice among genotypes for Sasa-UBA-3UTR were observed (ANCOVA, $F_{16}=2.2$, $\mathrm{p}=0.0046)$; however, weight explained a large proportion of the variation $\left(F_{1}=63.8, \mathrm{p}<0.0001\right)$. Pair-wise post hoc tests for abundance of $L$. salmonis revealed that all significant pair-wise tests involved the homozygous genotype $318 / 318$. This genotype displayed a significantly higher abundance of L. salmonis in 9 of the 16 pair-wise tests against other genotypes. No other genotype pairs were significantly different from each other. The 318/318 genotype was only present in Family 2. Coincidently, this family (Table 1) and genotype displayed the highest average weight of all families and genotypes (Fig. 2).

Significant differences in abundance of lice for the Sasa-DAA-3UTR genotype was observed in the pooled material (ANCOVA, $F_{12}=2.1, \mathrm{p}=0.016$ ); however, similar to the results for Sasa-UBA-3UTR, weight was of greater significance $\left(F_{1}=90.0, \mathrm{p}<0.0001\right)$ (Fig. 2$)$. In 

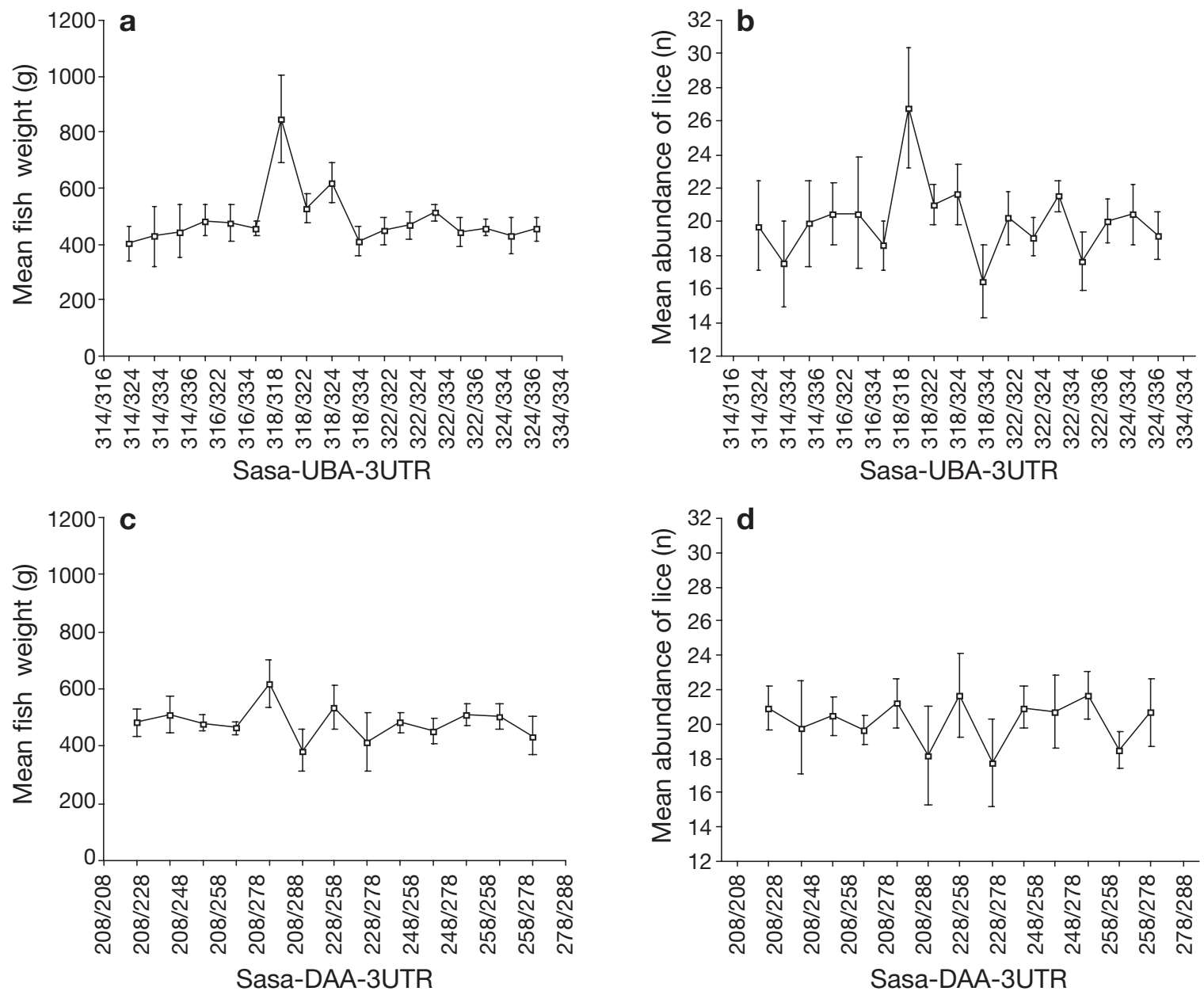

Fig. 2. Salmo salar and Lepeophtheirus salmonis. Relationship between genotype and (a,c) fish weight and (b,d) abundance of sea lice for Sasa-UBA-3UTR and Sasa-DAA-3UTR for fish representing 11 pooled families. Vertical bars denote 95\% confidence intervals

this instance, none of the post hoc pair-wise tests for abundance of lice were significant. For both SasaUBA-3UTR and Sasa-DAA-3UTR, a pattern suggesting a link between average weight for fish displaying a given genotype and abundance of Lepeophtheirus salmonis for that genotype is evident (Fig. 2).

\section{Genotype vs. abundance of Lepeophtheirus salmonis: within families}

Significant relationships between Sasa-UBA-3UTR or Sasa-DAA-3UTR genotype and abundance of lice were observed in 3 of the 11 families studied (Table 2). In Family 3, a significant relationship between abundance of Lepeophtheirus salmonis and genotype was observed for Sasa-UBA-3UTR (ANCOVA, $F_{\text {Genotype } 3=}=$ $\left.6.9, \mathrm{p}=0.01, F_{\text {Weight } 1}=11.6, \mathrm{p}=0.001\right)$. A significant relationship between the abundance of $L$. salmonis and the Sasa-DAA-3UTR genotype was also observed in Family 3 (ANCOVA, $F_{\text {Genotype } 3}=3.2, \mathrm{p}=0.027$, $\left.F_{\text {Weight } 1}=11.4, \mathrm{p}=0.001\right)$. Pair-wise post hoc tests indicated significant differences in abundance of lice between genotypes 208/228 and 208/248 ( $p=0.045$ ) and between genotypes 208/248 and 228/258 ( $\mathrm{p}=$ 0.003). In Family 4, a significant relationship between the Sasa-UBA-3UTR genotype and abundance of L. salmonis was observed (ANCOVA, $F_{\text {Genotype } 3}=3.1$, $\left.\mathrm{p}=0.029, F_{\text {Weight } 1}=2.0, \mathrm{p}=0.16\right)$. Pair-wise post hoc tests indicated significant differences in abundance of lice between genotypes 322/336 and 314/336 ( $\mathrm{p}=$ 0.04 ) and between genotypes 316/322 and 322/336 ( $p=0.03$ ). In Family 6, a significant relationship between the Sasa-DAA-3UTR genotype and abundance of L. Salmonis was observed (ANCOVA, $F_{\text {Genotype } 3=}=$ 4.5, $\left.\mathrm{p}=0.005, F_{\text {Weight } 1}=16.7, \mathrm{p}<0.0001\right)$. Pair-wise post hoc tests indicated that the genotypes 208/258 and $248 / 278$ were significantly different $(p=0.004)$. In 
Table 2. Salmo salar and Lepeophtheirus salmonis. Families in which significant associations between sea lice abundance and genotype were detected for Sasa-UBA-3UTR or Sasa-DAA-3UTR

\begin{tabular}{|c|c|c|c|c|c|}
\hline Family & Marker & Genotype & $\begin{array}{c}\text { Abundance } \\
\text { of sea lice } \\
\text { N (SD) }\end{array}$ & $\begin{array}{l}\text { Mean } \\
\text { weight } \\
\text { g (SD) }\end{array}$ & $\begin{array}{c}\text { Observed } \\
\text { no. } \\
\text { of fish }\end{array}$ \\
\hline 3 & Sasa-UBA-3UTR & $\begin{array}{l}322 / 334 \\
334 / 334\end{array}$ & $\begin{array}{l}21.4(0.8) \\
17.5(0.9)\end{array}$ & $\begin{array}{l}548.8(25.7) \\
474.2(26.7)\end{array}$ & $\begin{array}{l}39 \\
36\end{array}$ \\
\hline 3 & Sasa-DAA-3UTR & $\begin{array}{l}208 / 228 \\
208 / 248 \\
228 / 258 \\
248 / 258\end{array}$ & $\begin{array}{l}19.9(1.2) \\
15.2(1.3) \\
21.7(1.0) \\
18.8(1.3)\end{array}$ & $\begin{array}{l}590.9(35.9) \\
419.3(41.9) \\
534.6(32.7) \\
481.6(39.2)\end{array}$ & $\begin{array}{l}19 \\
14 \\
23 \\
16\end{array}$ \\
\hline 4 & Sasa-UBA-3UTR & $\begin{array}{l}314 / 316 \\
314 / 336 \\
316 / 322 \\
322 / 336\end{array}$ & $\begin{array}{l}19.8(1.2) \\
20.5(1.1) \\
20.9(1.3) \\
16.0(1.2)\end{array}$ & $\begin{array}{l}402.4(30.5) \\
484.8(27.8) \\
488.6(33.5) \\
416.7(31.2)\end{array}$ & $\begin{array}{l}24 \\
29 \\
20 \\
23\end{array}$ \\
\hline 6 & Sasa-DAA-3UTR & $\begin{array}{l}208 / 248 \\
208 / 258 \\
248 / 278 \\
258 / 278\end{array}$ & $\begin{array}{l}19.0(1.0) \\
16.3(1.1) \\
21.7(1.2) \\
17.9(0.9)\end{array}$ & $\begin{array}{l}463.3(18.3) \\
450.3(20.8) \\
455.0(22.8) \\
446.6(17.5)\end{array}$ & $\begin{array}{l}31 \\
24 \\
20 \\
34\end{array}$ \\
\hline
\end{tabular}

\section{Genotype vs. abundance of Lepeophtheirus salmonis: composite genotypes in pooled families}

In the pooled material, a total of 12 composite genotypes (Sasa-UBA-3UTRSasa-DAA-3UTR) were exhibited in over 20 individuals. Only these composite genotypes were analysed in the pooled material for the potential relationship between composite genotype and susceptibility to Lepeophtheirus salmonis. Significant overall differences in abundances of $L$. salmonis were observed among the 12 composite genotypes (ANCOVA, $F_{11}=$ $2.1, \mathrm{p}=0.022)$; however, fish weight determined a large proportion of the observed variation $\left(F_{1}=34.3, \mathrm{p}<0.0001\right)$ (Fig. 3). Post hoc tests revealed that the composite Genotype 6 (322/324258/278) displayed a significantly lower

all 4 instances where significant trends within family were observed, a G-test was applied to test for random sampling of alleles within each family. Results of all G-tests demonstrated random sampling (all $\mathrm{p}$-values $>0.1$ ).

With the exception of the observation in Family 6, all genotypes displaying significantly lower lice abundances as demonstrated though pair-wise post hoc tests were also smaller in average weight compared with the genotypes from which they differed (Table 2). In Family 6, no differences in mean weight were observed between the pair of genotypes 208/258 and 248/278 (Table 2). abundance of $L$. salmonis than did composite Genotype 8 (322/334-208/258), but no other pair-wise comparisons were significant. Investigating further, the composite Genotype 322/324-258/278 consisted of fish from Families 2 ( $\mathrm{n}=7$, mean abundance $=21.3), 8(\mathrm{n}=9$, mean abundance $=13.3$ ) and $14(\mathrm{n}=8$, mean abundance 18.0), whilst composite Genotype 322/334-208/258 consisted of fish from Families $8(\mathrm{n}=2$, mean abundance $=17.0), 9$ ( $\mathrm{n}=7$, mean abundance $=23.4)$ and $11(\mathrm{n}=17$, mean abundance $=23.8$ ). Clearly, the low abundance of $L$. salmonis observed on the 9 fish from Family 8 was responsible for creating the difference in abundance of lice between the composite genotypes.
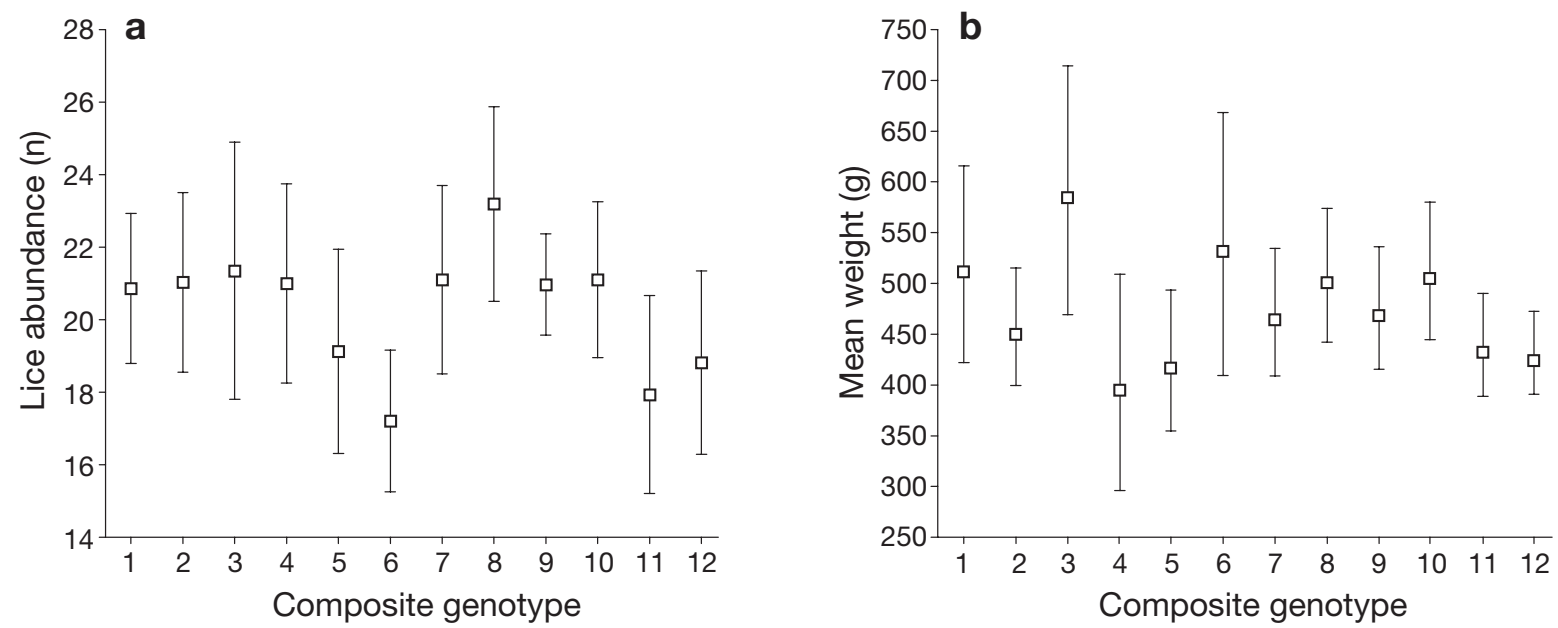

Fig. 3. Salmo salar and Lepeophtheirus salmonis. Relationship between composite genotype and (a) mean abundance of sea lice and (b) fish weight for 12 composite genotypes (Sasa-UBA-3UTR-Sasa-DAA-3UTR) originating from 11 full-sibling families. Composite genotypes: $1=318 / 322-208 / 208,2=318 / 322-208 / 258,3=318 / 324-208 / 258,4=322 / 324-208 / 208$, $5=322 / 324-208 / 258,6=322 / 324-258 / 278,7=322 / 334-208 / 248,8=322 / 334-208 / 258,9=322 / 334-248 / 258,10=322 / 334-$ 258/258, $11=324 / 334-208 / 258,12=324 / 334-258 / 278$. Vertical bars denote $95 \%$ confidence intervals 


\section{DISCUSSION}

To our knowledge, this study represents the first investigation of MHC variation and susceptibility to the sea louse Lepeophtheirus salmonis. Differences in abundance of L. salmonis were observed among genotypes for the polymorphic markers Sasa-UBA-3UTR (MHC Class I) and Sasa-DAA-3UTR (MHC Class II). Differences were observed within individual families, within the pooled material, and among composite genotypes within the pooled material. However, the majority of the observed trends were linked with variation in mean fish size between genotypes. Nevertheless, a relationship between the Sasa-DAA-3UTR genotype and abundance of lice within Family 6 was observed, and this was not influenced by fish size or family background genetic variation. Consequently, these data provide evidence suggesting that $\mathrm{MHC}$ is linked with susceptibility to L. Salmonis. However, the extent and significance of this involvement, and whether or not this represents direct or indirect involvement, is difficult to conclude from this study.

The link between the polymorphic repeat marker and coding region, in particular that for Sasa-UBA, is unpredictable and varies among strains and populations. A recombination signal exists in the intron between the $\alpha 1$ and $\alpha 2$ domains so that $\alpha 1$ domains are shifted between different $\alpha 2$ domains and downstream sequences, explaining part of this instability (Shum et al. 2001). However, recombination within the marker itself has been observed, with one Sasa-UBA allele having different markers in 2 different populations (authors' unpubl. data). Previous studies also showed that 1 marker may also be linked to multiple alleles, as for instance the SasaUBA-3UTR $322 \mathrm{bp}$ marker, which represented the alleles $U B A^{*} 0201$, $U B A^{*} 0301, \quad U B A^{*} 0401, U B A^{*} 0801$ and $U B A^{*} 1201$ (Grimholt et al. 2003). There is no knowledge on linkage between marker and coding region for the group of fish in the present study. The SasaDAA-3UTR alleles 208, 228, 248, 258, 278, 288 bp have previously been linked with the $\alpha-\beta$ haplotypes $D A A^{*} 0201 /$ $D A B^{*} 0201, D A A^{*} 0101 / D A B^{*} 0801, D A A^{*} 0301 / D A B^{*}$ 0401， $D A A^{*} 0401 / D A B^{*} 0701 ， D A A^{*} 0501 / D A B^{*} 0301$ and $D A A^{*} 0601 / D A B^{*} 0601$, respectively. Whether or not this stability exists within the present population is unknown; however, if it did, then the genotype displaying lowest abundance of lice in Family 6 would be $D A A^{*} 0201 / D A B^{*} 0201-D A A^{*} 0401 / D A B{ }^{*} 0701$. In addition, it is not possible to exclude the possibility that the families challenged displayed different but 'functionally similar' alleles within these markers by chance. Consequently, the possibility cannot be excluded that a stronger link between MHC and abundance of lice would be observed by performing the analysis based on coding region, or by performing this study on a group of fish displaying different or greater diversity of alleles (such as a wild population).

Associations between allelic variation in the MHC in Atlantic salmon and susceptibility to bacterial (Langefors et al. 2001, Grimholt et al. 2003) and viral (Ozaki et al. 2001, Palti et al. 2001, Grimholt et al. 2003, Miller et al. 2004, Kjoglum et al. 2006) pathogens have been reported. In addition, a statistical relationship between severity of amoebic gill disease (AGD) and MHC variation has been reported in Atlantic salmon (Wynne et al. 2007). The present experiment was similar in design to the study elucidating the link between MHC variation and susceptibility to both furunculosis and infectious salmon anemia (ISA) (Grimholt et al. 2003), and the link between MHC variation and susceptibility to AGD (Wynne et al. 2007). However, within the present study, a fewer number of families and larger number of fish representing each family were prioritised for screening. This design was chosen owing to the fact that the within-family component of variation in abundance of Lepeophtheirus salmonis is much greater than the between-family abundance of $L$. salmonis (Glover et al. 2005, present study), in addition to the fact that the within-family analysis is less influenced by background family genetic variation.

In order to verify the influence of the Sasa-DAA3UTR genotype on the abundance of Lepeophtheirus salmonis, further experimentation is required. Verification of MHC involvement could be achieved by a strategy similar to that used to verify specific MHC Class I and II allele combinations affecting resistance to ISA in Atlantic salmon (Kjoglum et al. 2006) or, alternatively, by testing within multiple families that display the Sasa-DAA-3UTR 208/258 and 248/278 heterozygotes.

For furunculosis, the heritability of susceptibility (see Gjedrem 2000) is considerably higher than that reported for sea lice (Mustafa \& MacKinnon 1999, Glover et al. 2005, Kolstad et al. 2005) where nongenetic effects dominate. Clearly, finding a link between potential genetic markers and susceptibility to Lepeophtheirus salmonis presents a more challenging task than it would in the case of a pathogen that displays a higher heritability of susceptibility and where the phenotype is more closely linked with the genotype. However, fundamental differences in hostpathogen relationships exist between external parasites such as sea lice, which are largely protected from the host's immune system, and bacterial and viral pathogens that enter the organism or its cells. A recent study of AGD in Atlantic salmon demonstrated a link between MHC variation and severity of infection (Wynne et al. 2007). However, similar to the results of the present study, the associations observed by these 
authors were weak. Nevertheless, the fact that a link between the MHC and parasite susceptibility has been observed in several fish species (e.g. Kurtz et al. 2004, Simkova et al. 2006) supports the idea that the MHC has the potential to be linked with susceptibility to L. salmonis.

Despite the fact that specific antibodies to Lepeophtheirus salmonis have been observed in Atlantic salmon (Grayson et al. 1991, 1995), the acquired immune response to sea lice is apparently weak. This is illustrated by the fact that Atlantic salmon are easily reinfected with high levels of sea lice (e.g. Glover et al. 2004a). In an experimental study of L. salmonis infection in coho salmon, Johnson \& Albright (1992a) observed a significantly higher infection level in immune-suppressed fish compared with control fish, and that this difference was primarily mediated by the apparent suppression of inflammatory response and the development of epithelial hyperplasia. Likewise, in a comparison of susceptibility to L. salmonis among 3 salmonid species, Johnson \& Albright (1992b) demonstrated that Atlantic salmon displayed a significantly greater infection level of $L$. salmonis compared with both coho and Chinook Oncorhynchus tshawytscha salmon, and that these differences were primarily related to the lack of host-tissue responses in Atlantic salmon compared with the other species.

In repeated challenge experiments (Glover et al. 2004a, Glover \& Skaala 2006), individual salmon displaying lower than average infection levels in a first challenge (i.e. individuals identified as 'resistant') did not necessarily display a lower than average infection level in a second or third challenge. Consequently, unidentified factors in addition to fish size appear to be dominating in determining individual lice abundance levels in challenge tests in both cages and tanks. Clearly, it is not possible to exclude the possibility that the results of the present study may be stock specific. However, a combination of the low observed level of MHC involvement in Lepeophtheirus salmonis abundance, the fact that heritability of lice abundance is low or at best moderate (Mustafa \& MacKinnon 1999, Glover et al. 2005, Kolstad et al. 2005), and that Atlantic salmon are regarded as highly susceptible to L. salmonis, it can be argued that it is unlikely that the MHC has any major effect on susceptibility to sea lice. This requires further study.

In summary, differences in abundance of Lepeophtheirus salmonis were observed among genotypes for the polymorphic repeat markers located in the 3UTR of the Sasa-UBA and Sasa-DAA genes. When associations caused by the link with fish size were excluded, the only clear evidence of interaction between MHC and abundance of $L$. salmonis was observed in a single family for Sasa-DAA-3UTR. It is clearly difficult to indi- cate the significance of this result, and further study is required to categorise the extent and nature of involvement of the MHC in susceptibility to sea lice.

Acknowledgements. The Norwegian Research Council (NFR) and Aqua Gen AS are gratefully acknowledged for financially supporting this study. The assistance of technical staff at Aqua Gen AS and M. Arnesen during sampling is acknowledged. We thank referees for their helpful comments.

\section{LITERATURE CITED}

Deady S, Varian SJA, Fives JM (1995) The use of cleaner-fish to control sea lice on 2 Irish salmon (Salmo-salar) farms with particular reference to wrasse behaviour in salmon cages. Aquaculture 131:73-90

Fallang A, Ramsay JM, Sevatdal S, Burke JF, Jewess P, Hammell KL, Horsberg TE (2004) Evidence for occurence of an organophosphate-resistant type of sea lice (Lepeophtheirus salmonis Kroyer). Pest Manage Sci 60:1163-1170

Frost P, Beiring E, Moros C, Nilsen F (2006) Utvikling av vaksine mot lakselus. Fisk Havet 2:102-106

Genna RL, Mordue W, Pike AW, Mordue AJ (2005) Light intensity, salinity, and host velocity influence presettlement intensity and distribution on hosts by copepodids of sea lice, Lepeophtheirus salmonis. Can J Fish Aquat Sci 62:2675-2682

Gjedrem T (2000) Genetic improvement of cold-water fish species. Aquac Res 31:25-33

Gjedrem T, Gjøen HM, Gjerde B (1991) Genetic origin of Norwegian farmed Atlantic salmon. Aquaculture 98:41-50

Glover KA, Skaala $\varnothing(2006)$ Temporal stability of sea louse Lepeophtheirus salmonis Krøyer populations on Atlantic salmon Salmo salar L. of wild, farm and hybrid parentage. Aquaculture 68:1795-1807

Glover KA, Nilsen F, Skaala Ø, Taggart JB, Teale AJ (2001) Differences in susceptibility to sea lice infection between a sea run and a freshwater resident population of brown trout. J Fish Biol 59:1512-1519

Glover KA, Skaala Ø, Nilsen F, Olsen R, Taggart JB, Teale AJ (2003) Differing susceptibility of anadromous brown trout Salmo trutta L. populations to salmon lice infections. ICES J Mar Sci 60:1-10

Glover KA, Hamre LA, Skaala Ø, Nilsen F (2004a) A comparison of sea louse (Lepeophtheirus salmonis) infection levels in farmed and wild Atlantic salmon (Salmo salar L.) stocks. Aquaculture 232:41-52

Glover KA, Nilsen F, Skaala Ø (2004b) Individual variation in sea lice (Lepeophtheirus salmonis) infection on Atlantic salmon (Salmo salar). Aquaculture 241:701-709

Glover KA, Aasmundstad T, Nilsen F, Storset A, Skaala $\varnothing$ (2005) Variation of Atlantic salmon families (Salmo salar L.) in susceptibility to the sea lice Lepeophtheirus salmonis and Caligus elongatus. Aquaculture 245:19-30

Grayson TH, Jenkins PG, Wrathmell AB, Harris JE (1991) Serum responses to the salmon louse, Lepeophtheirus salmonis (Krøyer, 1838), in naturally infected salmonids and immunized rainbow trout, Oncorhynchus mykiss (Walbaum), and rabbits. Fish Shellfish Immunol 1:141-155

Grayson TH, John RJ, Wadsworth S, Greaves K, Cox D, Wrathmell AB, Gilpin ML, Harris JE (1995) Immunization of Atlantic salmon against the salmon louse: identification of antigens and effects on louse fecundity. J Fish Biol (Suppl A) 47:85-94 
Grimholt U, Drablos F, Jorgensen SM, Høyheim B, Stet RJM (2002) The major histocompatability class I locus in Atlantic salmon (Salmo salar L.): polymorphism, linkage analysis and protein modelling. Immunogenetics 54: 570-581

Grimholt U, Larsen S, Nordmo R, Midtlyng P, Kjøglum S, Storset A, Sæbø S, Stet RJM (2003) MHC polymorphism and disease resistance in Atlantic salmon (Salmo salar); facing pathogens with single expressed major histocompatibility class I and class II loci. Immunogenetics 55: $210-219$

Jaworski A, Holm JC (1992) Distribution and structure of the population of sea lice, Lepeophtheirus salmonis Krøyer, on Atlantic salmon, Salmo salar, under typical rearing conditions. Aquac Fish Manage 23:577-589

Johnson SC, Albright LJ (1992a) Effects of cortisol implants on the susceptibility and the histopathology of the responses of naïve coho salmon Oncorhynchus kisutch to experimental infection with Lepeophtheirus salmonis (Copepoda: Caligidae). Dis Aquat Org 14:195-205

Johnson SC, Albright LJ (1992b) Comparative susceptibility and histopathology of the response of naive Atlantic, Chinook and coho salmon to experimental infection with Lepeophtheirus salmonis (Copepoda: Caligidae). Dis Aquat Org 14:179-193

Jones MW, Sommerville C, Wootten R (1992) Reduced sensitivity of the salmon louse, Lepeophtheirus salmonis, to the organophosphate dichlorvos. J Fish Dis 15:197-202

Kjoglum S, Larsen S, Bakke HG, Grimholt U (2006) How specific MHC class I and class II combinations affect disease resistance against infectious salmon anaemia in Atlantic salmon (Salmo salar). Fish Shellfish Immunol 21:431-441

Kolstad K, Heuch PA, Gjerde B, Gjedrem T, Salte R (2005) Genetic variation in resistance of Atlantic salmon (Salmo salar) to the salmon louse Lepeophtheirus salmonis. Aquaculture 247:145-151

Kurtz J, Kalbe M, Aeschlimann PB, Haberli MA, Wegner KM, Reusch TBH, Milinski M (2004) Major histocompatability complex diversity influences parasite resistance and innate immunity in sticklebacks. Proc R Soc Lond B 271: 197-204

Langefors A, Lohm J, Grahn M, Andersen O, Von Schantz $\mathrm{T}$ (2001) Association between major histocompatibility complex class IIB alleles and resistance to Aeromonas salmonicida in Atlantic salmon. Proc R Soc Lond B 268: 479-485

Miller KM, Winton JR, Schulze AD, Purcell MK, Ming TJ (2004) Major histocompatibility complex loci are associated with susceptibility of Atlantic salmon to infectious hematopoietic necrosis virus. Environ Biol Fish 69:307-316

Mordue AJ, Pike AW (2002) Salmon farming: towards an integrated pest management strategy for sea lice. Pest Manage Sci 58:513-514

Mustafa A, MacKinnon BM (1999) Genetic variability in susceptibility of Atlantic salmon to the sea louse Caligus elongatus Nordmann, 1832. Can J Zool 77:1332-1335

Ozaki A, Sakamoto T, Khoo S, Nakamura K, Coimbra MR, Akutsu T, Okamoto N (2001) Quantitative trait loci (QTLs) associated with resistance/susceptibility to infectious pancreatic necrosis virus (IPNV) in rainbow trout (Oncorhynchus mykiss). Mol Genet Genomics 265:23-31

Palti Y, Nichols KM, Waller KI, Parsons JE, Thorgaard GH (2001) Association between DNA polymorphisms tightly linked to MHC class II genes and IHN virus resistance in backcrosses of rainbow and cutthroat trout. Aquaculture 194:283-289
Raynard RS, Bricknell IR, Billingsley, PF, Nisbet AJ, Vigneau A, Sommerville C (2002) Development of vaccines against sea lice. Pest Manage Sci 58:569-575

Roper J, Grayson TH, Jenkins PG, Hone JV, Wrathnell AB, Russell PM, Harris JE (1995) The immunocythochemical localisation of potential candidate vaccine antigens from the salmon louse Leoeophtheirus salmonis (Krøyer, 1832). Aquaculture 132:221-232

Roth M, Richards RH, Sommerville C (1993) Current practices in the chemotherapeutic control of sea lice infestations in aquaculture-a review. J Fish Dis 16:1-26

Sevatdal S, Horsberg TE (2003) Determination of reduced sensitivity in sea lice (Lepeophtheirus salmonis Krøyer) against the pyrethroid deltamethrin using bioassays and probit modelling. Aquaculture 218:21-31

Shum BP, Guethlein L, Flodin LR, Adkison MA and 5 others (2001) Modes of salmonid MHC class I and II evolution differ from the primate paradigm. J Immunol 160: 3297-3308

Simkova A, Ottova E, Morand S (2006) MHC variability, lifetraits and parasite diversity of European cyprinid fish. Evol Ecol 20:465-477

Stet RJM, De Vries B, Mudde K, Hermsen TT, Van Heerwaarden J, Shum BP, Grimholt U (2002) Unique haplotypes of co-segregating major histocompatibility class II $A$ and class II $B$ alleles in Atlantic salmon (Salmo salar) give rise to diverse class II genotypes. Immunogenetics 54:320-331

Todd CD, Walker AM, Hoyle JE, Northcott SJ, Walker AF, Ritchie MG (2000) Infestations of wild adult Atlantic salmon (Salmo salar L.) by the ectoparasitic copepod sea louse Lepeophtheirus salmonis Kroyer: prevalence, intensity and the spatial distribution of males and females on the host fish. Hydrobiologica 429:181-196

Treasurer JM (2002) A review of potential pathogens of sea lice and the application of cleaner fish in biological control. Pest Manag Sci 58:546-558

Treasurer JM, Wadsworth S, Grant A (2000) Resistance of sea lice, Lepeophtheirus salmonis (Krøyer), to hydrogen peroxide on farmed Atlantic salmon, Salmo salar L. Aquac Res 11:855-860

Tucker CS, Sommerville C, Wooten R (2002) Does size really matter? Effects of fish surface area on the settlement and initial survival of Lepeophtheirus salmonis, an ectoparasite of Atlantic salmon Salmo salar. Dis Aquat Org 49: $145-152$

Tully O, McFadden Y (2000) Variation in sensitivity of sea lice (Lepeophtheirus salmonis (Krøyer)) to dichlorvos on Irish salmon farms in 1991-1992. Aquac Res 31:849-854

Tully O, Daly P, Lysaght S, Deady S, Varian SJA (1996) Use of cleaner-wrasse (Centrolabrus exoletus (L) and Ctenolabrus rupestris (L)) to control infestations of Caligus elongatus Nordmann on farmed Atlantic salmon. Aquaculture 141:11-24

Wegner KM, Kalbe G, Raunch J, Kurtz H, Schaschl H, Reusch $\mathrm{BH}$ (2006) Genetic variation in MHC class II expression and interactions with MHC sequence polymorphism in three-spined sticklebacks. Mol Ecol 15:1153-1164

Wootten R, Smith JW, Needham EA (1982) Aspects of the biology of the parasitic copepods Lepeophtheirus salmonis and Caligus elongatus on farmed salmonids, and their treatment. Proc R Soc Edinb B 81:185-197

Wynne JW, Cook MT, Nowak BF, Elliott NG (2007) Major histocompatibility polymorphism associated with resistance towards ameobic gill disease in Atlantic salmon (Salmo salar L.). Fish Shellfish Immunol 22:707-717 